in the elucidation of primary morbidity. The differentiation between changes due to nephrosclerosis, chronic nephritis, and chronic pyelonephritis can be difficult, and the final diagnosis has been reached on correlations between histological, radiological, and bacteriological findings, together with the clinical picture. Focal nephritis has been associated with hypertension (Kincaid-Smith, 1966). The exact pathophysiological significance of this is not clear, though a familial type with dominant inheritance associated with severe hypertension has been described. Finally, this study emphasizes the need to investigate young hypertensive patients, especially those who are under the age of 35 or who have fundal grades III and IV hypertension, as a large proportion of these will be found to have an underlying cause.
We thank Dr. Tan Kheng Khoo, of the department of pathology of Outram Road General Hospital, Singapore, for his help in interpreting the renal histology, and the radiologists of Outram Road General Hospital, especially Dr. S. F. Yu, for their generous co-operation in the radiological examinations done in this study.

Breckenridge, A., Preger, L., Reflery, C. T., and Laws, J. W. (1967) Quarterly fournal of Medicine, 36, 549 .

Danaraj, T. J., and Ong, W. H. (1959). Circulation, 20, 856.

Fenton, S. S. A., Lyttle, J. A., and Pantridge, J. F. (1966). Lancet, 2, 117. Heptinstall, R. H. (1966). Pathology of the Kidney. London, Churchill. Keith, N. M., Wagener, H. P., and Barker, N. W. (1939). Americal fourna of the Medical Sciences, $197,332$.

Kincaid-Smith, P. (1966). In Antihypertensive Therapy, ed. F. Gross, p. 485. Berlin, Springer.

Platt, R. (1948). Quarterly fournal of Medicine, 17, 82.

Poutasse, E. F., and Dustan, H. P. (1957). Fournal of the American Medical Association, 165, 1521 .

Seldinger, S. I. (1953). Acta Radiologica, 39, 368.

\title{
Reversible Cerebral Oedema Complicating Diabetic Ketoacidosis
}

\author{
ALLAN L. METZGER, ${ }^{*}$ M.D. ; ARTHUR H. RUBENSTEIN, $†$ M.B., B.CH., M.R.C.P.
}

\begin{abstract}
Cummary: A young man with diabetic ketoacidosis developed the clinical features of cerebral oedema. This resolved without specific treatment. The mortality from ketoacidosis might be reduced if the syndrome was suspected and treated earlier.
\end{abstract}

\section{Introduction}

The mortality from diabetic ketoacidosis varies between 8 and $16 \%$, depending on the age of the population studied (Greenway and Read, 1958; Fitzgerald et al., 1961; Young and Bradley, 1967). At necropsy many of these patients show the pathological characteristics of cerebral oedema. This syndrome, however, has seldom been considered or diagnosed by the clinician, and the pertinent literature deals mainly with its pathogenesis and irreversible course. We wish to draw attention to a patient with this condition who recovered spontaneously. Retrospective consideration of the clinical progress of other patients with diabetic ketoacidosis leads us to believe that this syndrome may not be very uncommon.

\section{Case Report}

An 18-year-old negro was brought to Billings Hospital emergency room moderately confused and lethargic. His wife stated that until two weeks previously he had been in excellent health. He then developed weakness, malaise, weight loss, shortness of breath, poly uria, and polydipsia. He complained of abdominal pain, nausea, and recurrent vomiting. There was no history of trauma or infection. His maternal grandmother had diabetes mellitus requiring insulin.

On physical examination he was lethargic, thin, and profoundly weak, with pronounced Kussmaul respiration. His pulse was $136 /$ minute, blood pressure $115 / 70$, respiration $36 /$ minute, and rectal temperature $37^{\circ} \mathrm{C}$. He was dehydrated, and acetone was noted in his breath.

Initial laboratory data included a blood sugar of $765 \mathrm{mg}$. and blood urea nitrogen of $22 \mathrm{mg}$. $/ 100 \mathrm{ml}$; the serum sodium was 130 $\mathrm{mEq}$, potassium $5.2 \mathrm{mEq}$, chloride $92 \mathrm{mEq}$, and bicarbonate less than $10 \mathrm{mEq} / \mathrm{l}$. The calculated serum osmolality was 328 mOsm/l. (Dillon et al., 1936). Serum acetone was 3+ at 1:2 dilution with Acetest tablets. Arterial blood gases were $\mathrm{CO}_{2} 12 \mathrm{~mm}$.

- Resident in Medicine.

$\dagger$ Associate Professor of Medicine.

University of Chicago, Chicago, Illinois. and $\mathrm{O}_{2} 118 \mathrm{~mm}$. $\mathrm{Hg}$; the $\mathrm{pH}$ was $7 \cdot 25$. The packed cell volume was $51 \%$ and the white blood count 21,500 cells/cu.mm., with $95 \%$ polymorphonuclear leucocytes.

Intravenous therapy was initiated with 1 litre of $0.45 \%$ saline to which $44 \mathrm{mEq}$ of sodium as bicarbonate was added; concomitantly, 100 units of regular insulin was injected subcutaneously. Over the first four hours he received 3 litres of $0.45 \%$ saline and $88 \mathrm{mEq}$ of sodium bicarbonate. The blood sugar fell to $376 \mathrm{mg} . / 100 \mathrm{ml}$., serum acetone decreased to $1+$ without dilution, and the serum bicarbonate rose to $10 \mathrm{mEq} / 1$. Serum sodium, potassium, and chloride levels approached normal values. At this time he was alert, but complained of nausea and vomited. During the next four hours 50 units of regular insulin, 2.5 litres of $5 \%$ dextrose in $0.33 \%$ saline, $88 \mathrm{mEq}$ of sodium bicarbonate, and 80 $\mathrm{mEq}$ of potassium chloride were given. The blood sugar fell to $240 \mathrm{mg} . / 100 \mathrm{ml}$., serum bicarbonate increased to $21 \mathrm{mEq} / 1$., and serum acetone was negative. His mental status improved noticeably and headache, nausea, and vomiting abated. He remained afebrile and had a satisfactory urinary output.

About 10 hours after admission his mental status suddenly worsened despite near normal serum electrolyte (sodium $133 \mathrm{mEq}$, potassium $3.7 \mathrm{mEq}$, chloride $101 \mathrm{mEq}$, bicarbonate $21 \mathrm{mEq} / 1$.) and blood glucose values $(200 \mathrm{mg} . / 100 \mathrm{ml}$.). The serum osmolality was $295 \mathrm{mOsm} / 1$. He complained of headache and became lethargic, confused, and difficult to arouse. Moderate neck stiffness was elicited, but neither papilloedema nor localizing neurological signs were observed. Lumbar puncture revealed an opening pressure of $420 \mathrm{~mm}$. and a closing pressure of $410 \mathrm{~mm}$.; there were no cells, and all cultures were subsequently negative. The cerebrospinal fluid protein was $25 \mathrm{mg}$. and glucose $270 \mathrm{mg} . / 100 \mathrm{ml}$. The simultaneous blood sugar value was $176 \mathrm{mg} . / 100 \mathrm{ml}$. A diagnosis of cerebral oedema was made, and though treatment with mannitol and steroids was considered we decided to observe his course for a short time before their administration. Gradually over the next four hours the patient improved: he became less irritable, was more alert, and began to converse rationally and spontaneously. Thereafter he showed steady improvement, and some eight hours after the lumbar puncture his mental status returned to normal. The remainder of his stay in hospital was uneventful, and after two weeks he was discharged on 24 units of insulin injection and 24 units of protamine zinc insulin injection daily. At later outpatient visits neurological examination was negative and his mental status was normal.

\section{Discussion}

This report illustrates the occurrence of cerebral oedema complicating the management of moderately severe diabetic ketoacidosis. The clinical picture of mental deterioration 
showed no evidence of circulatory collapse or infection and serum electrolytes and blood sugar values were only minimally deranged. The case is unusual because of the recognition and documentation of the syndrome and its subsequent spontaneous reversibility.

Cerebral oedema complicating diabetic coma has only recently received significant attention (Fitzgerald et al., 1961; Young and Bradley, 1967; Hayes and Woods, 1968). These authors reported six patients with the characteristic clinical picture; all were young (aged 9 to 28), with moderately severe ketoacidosis (blood sugar 500 to $800 \mathrm{mg} . / 100 \mathrm{ml}$.), and after an initial short period of improvement (4 to 16 hours) mental deterioration and death occurred secondary to histologically proved cerebral oedema. It is of particular interest that the presence of cerebral oedema at necropsy had been noted in several earlier publications dealing with ketotic diabetics who died for "unexplained reasons" (Dillon et al., 1936; Di Benedetto et al., 1965; Hayes and Woods, 1968). Nevertheless, the clinical syndrome was neither recognized nor correlated with the pathological findings. Though Young and Bradley (1967) suggested that the occurrence of cerebral oedema in hyperglycaemic hyperosmolar coma was unlikely, Maccario et al. (1965) reported the development of this syndrome in such a patient who survived. In this context cerebral oedema has also been documented histologically in patients dving with hyperosmolar non-ketotic coma (Larcon et al., 1963; Bergoz and Hausser, 1964) and recognized in hypoglycaemic coma (Marks and Rose, 1965).

The pathogenesis of cerebral oedema in patients with diabetic ketoacidosis is still uncertain. Dehvdration, haemoconcentration, acidosis, and decreased cerebral blood flow lead to cerebral anoxia and suppression of aerobic metabolism (Meyer et al., 1965). Brain cells may become abnormally permeable to sodium ions, and water would follow owing to osmotic pressure gradients (Young and Bradley, 1967; Hayes and Woods, 1968); the result would be intracellular overhydration. Recent studies have suggested that increased activity of the polyol pathway in response to hyperglycaemia results in accumulation of osmotically active fructose and sorbitol in the brain (Clements et al., 1968). The time of occurrence of this complication also suggests many similarities to the disequilibrium syndrome, which may develop during dialysis. Though we have carefully assessed the rate at which our patient's osmolality, acidosis, and hyperglycaemia were corrected, as well as the quantities of sodium, bicarbonate, and water administered, we can find no features to distinguish his therapy from that of our patients who did not develop this syndrome.

Therapy usually recommended for cerebral oedema is urea or mannitol together with glucocorticoids (Matson, 1965). This regimen, however, has been tried with little success in a few instances of cerebral oedema complicating diabetic ketoacidosis (Young and Bradley, 1967). Because of the high mortality from the condition we feel that this mode of therapy needs further evaluation. If there was no improvement in a patient with cerebral oedema after a short period of observation, or if the patient was comatose at the time of diagnosis, we would recommend the use of these drugs. In our patient improvement was rapid and progressive after the diagnosis was made; for this reason, as well as the fact that anti-oedema agents have not always proved beneficial, therapy was withheld.

If this syndrome is to be recognized careful and frequent monitoring of the neurological status of patients treated for diabetic ketoacidosis is necessary. Posner et al. (1965) have drawn attention to the interrelationships of blood and cerebrospinal fluid acid-base balance in diabetic ketoacidosis uncomplicated by this syndrome. Simultaneous measurements of blood and cerebrospinal fluid glucose, osmolality, $p \mathrm{H}$, and electrolytes will undoubtedly facilitate our understanding and treatment of cerebral oedema.

\section{REFERENCES}

Bergoz, R., and Hausser, E. (1964). Lancet, 1, 116.
Clements, R. S., jun., Prockop, L. D., and Winegrad, A. I. (1968). Lancet, 2,
384. 384.

Di Benedetto, R. J., Crocco, J. A., and Soscia, J. L. (1965). Archives of Internal Medicine, 116, 74.

Dillon, E. S., Riggs, H. E., and Dyer, W. W. (1936). American fournal of the Medical Sciences, 192, 360.

Fitzgerald, M. G., O'Sullivan, D. J., and Malins, J. M. (1961). British Medical Fournal, 1, 247.

Greenway, J. M., and Read, J. (1958). Australasian Annals of Medicine, 7, 151.

Hayes, T. M., and Woods, C. J. (1968). British Medical Fournal. 4, 32 .

Larcon, A., Horiet, C., Vert, P., and Thibaut, G. (1963). Diabete, 11, 99. Maccario, M., Messis, C. P., and Vastola, E. F. (1965). Neurology (Minneapolis), 15, 195.

Marks, V., and Rose, F. C. (1965). Hypoglycaemia. Oxford, Blackwell

Scientific.
Matson, D. D. (1965). New England fournal of Medicine, 272, 626. Meyer, J. S., Gotoh, F., Ebihara, S., and Tomita, M. (1965). Neurology

Posner, J. B., Swanson, A. G., and Plum, F. (1965). Archives of Neurology, 12, 479.
Young, E., and Bradley, R. F. (1967). New England fournal of Medicine,
276, 665.

\section{Preliminary Communications}

\section{Free Amino-acid Concentrations in Fetal Fluids}

British Medical fournal, 1970, 3, 747-750

$S^{\text {un }}$ mmary: The pattern of free amino-acid concentrations in maternal venous plasma, fetal umbilical arterial plasma, fetal urine, and amniotic fluid at 15 to 20 weeks' gestation has been determined. Free amino-acid concentrations were greater in fetal plasma than in maternal plasma, amniotic fluid, or fetal urine.

The ratios of amino-acid concentrations in fetal umbilical arterial plasma and urine indicate that the fetal kidney can effectively conserve amino-acids, possibly reaching an adult level of competence in this respect.

There was little correlation between amino-acid concentrations in the fluids analysed with the exception of that between amniotic fluid and fetal urine.

\section{INTRODUCTION}

Patterns of urinary free amino-acid excretion have been established for adult man, the newborn infant, and a number of different animal species (Evered, 1956, 1967; O'Brien and Butterfield, 1963). Such patterns are characteristic but can be altered by pathological states. Thus urinary patterns may be disturbed by renal tubular defect or when plasma concentrations of individual or grouns of amino-acids exceed the renal tubular threshold (Dent, 1954).

The purbose of this paper is to describe the pattern of plasma and urinary amino-acid concentrations in the fetus during early pregnancy, to relate these to maternal amino-acid concentrations, and to assess their influence on the composition of amniotic fluid.

\section{Materials AND Methods}

Samples were obtained at hysterotomy pregnancy terminations between 15 and 20 weeks' gestation. The eight mothers 